\title{
LAS FUNCIONES DEL LENGUAJE DE JAKOBSON EN LA TITULACIÓN DEPORTIVA: ESTUDIO ESTILÍSTICO DE LA NACIÓN Y LA EXTRA
}

\author{
Ericka Vargas Castro
}

\section{(9) $\odot \Theta \Theta$}

Esta obra está bajo una licencia Creative Commons

Reconocimiento-No Comercial-Sin Obra Derivada 



\title{
LAS FUNCIONES DEL LENGUAJE DE JAKOBSON EN LA TITULACIÓN DEPORTIVA: ESTUDIO ESTILÍSTICO DE LA NACIÓN Y LA EXTRA
}

\author{
THE FUNCTIONS OF JAKOBSON'S LANGUAGE IN SPORTS \\ SEADLINES: AN STYLISTIC ANALYSIS OF LA NACIÓN AND LA EXTRA
}

\author{
Ericka Vargas Castro
}

\begin{abstract}
RESUMEN
En el siguiente artículo se estudian los titulares periodísticos dentro del esquema de la comunicación de Jakobson. Los titulares son enunciados producidos por un diario (el cual funciona como emisor) y transmiten un mensaje relacionado con una realidad, sea física o mental, a un destinatario, el lector. En el caso de los periódicos La Nación y La Extra, el código compartido es el español, pero se emplean diferentes subcódigos: mientras que el primer diario se caracteriza por el uso de un registro formal, en el segundo se prefiere el léxico informal propio del sociolecto al que se dirige el diario. Asimismo, se presupone que las funciones del lenguaje de Jakobson que deben prevalecer en los titulares son la referencial y la fática, pero en la sección deportiva se demostró que en ambos periódicos se utilizan titulares cuya forma podría vincularse con la función poética. Esto evidencia una mayor libertad en la sección deportiva para interactuar con el contenido del mensaje. Además, en el caso de La Extra, se registraron titulares en donde se enfatiza alguna de las otras funciones, ya sea la emotiva, la conativa o la metalingüística, por cuanto también se busca interactuar con el lector, incorporar rasgos subjetivos y emplear juegos lingüísticos con el fin de hacer el titular más atractivo. Palabras clave: análisis del discurso, funciones del lenguaje de Jakobson, titulares, discurso periodístico, La Nación, La Extra.
\end{abstract}

\begin{abstract}
The following article analyses headings according to the schema of verbal communication proposed by Jakobson. Headings are statements produced by a newspaper, the addresser, and they convey a message related to a reality, whether physical or mental, to the addressee, the reader. In the case of the newspapers La Nación and La Extra, the code is Spanish, but they differ in the selected subcodes: while La Nación is characterized by a formal register, in La Extra an informal style is preferred. Moreover, it is assumed that the functions of language of Jakobson that should prevail are referential and phatic, but in the sports section, in both types of newspaper, some headlines could be related to the poetic function. This implies more freedom in this section to interact with the content of the message. Nevertheless, in La Extra, there were some headings containing either the emotive, conative, or metalinguistic function as the predominant one. In those cases, the purpose is interacting with the reader, incorporating subjective traits, and using language games to make the heading more appealing, so that it can accomplish the objective of attracting and entertaining the reader.

Key words: Discourse Analysis, Jakobson's Functions of Language, Headlines, Printed Media, $L a$ Nación, La Extra.
\end{abstract}

M.L. Ericka Vargas Castro. Universidad de Costa Rica. Profesora interina. Escuela de Filología, Lingüística y Literatura. Costa Rica.

Correo electrónico: erickavargasucr@gmail.com

Recepción: 13- 05- 2014

Aceptación: 11- 08- 2014 


\title{
1. Introducción
}

La titulación periodística en prensa escrita es una clase de discurso que pertenece a la comunicación de masas, es decir, un emisor se dirige a una pluralidad de receptores (TusónValls, 2003, p. 47). La existencia de un público heterogéneo implica la necesidad de construir el mensaje con particular cuidado, pues el texto debe ser autosuficiente para transmitir un contenido, en principio referencial, de una manera óptima en términos de extensión y también de forma. Por ende, intervienen diversas etapas de producción que especializan el texto para insertarlo efectivamente en el contexto social al que se dirige y para adaptarlo al lector meta.

En el presente estudio, se identificarán los elementos que constituyen el titular como hecho discursivo y las subsecuentes funciones del lenguaje, a partir de las premisas de Jakobson (1984). Se pretende, de esta manera, describir los procesos generales que particularizan la producción noticiosa escrita y, a la vez, encontrar rasgos que permitan diferenciar los estilos de titulación de La Nación y La Extra, según la función que se privilegie en el título.

\subsection{Estudios sobre el discurso noticioso y el titular}

\author{
Martini y Luchessi (2004, p. 112) definen la noticia como \\ el relato de un hecho que implica una ruptura en el devenir cotidiano, la 'inercia' del mundo, por eso, en su \\ selección y construcción operan los criterios de novedad, imprevisibilidad, excepcionalidad y relevancia, \\ y los tiempos cortos, el compromiso del periodismo con la sociedad y la capacidad para trabajarla en un \\ proceso rutinario (eficaz).
}

Es, entonces, un producto discursivo orientado, por un lado, al lector, pues le da a conocer aspectos considerados socialmente como relevantes y a los cuales, en principio, no puede tener acceso directo (Martini, 2000, p. 15). Los hechos narrados deben cumplir con las expectativas del receptor y los imaginarios sociales, por cuanto la noticia es un trabajo articulado a nivel del mensaje. Asimismo, se centra en el emisor y los productores del trabajo, ya que la noticia no nace, sino que se construye. Al respecto, afirma Colombo (1997, p. 70): "no todas las noticias que tendrían que nacer nacen". Los criterios que permiten seleccionar un acontecimiento como noticia son las premisas de noticiabilidad, entre las cuales cabe mencionar la relevancia, la novedad, la excepcionalidad, el interés del público, la gravedad de lo ocurrido, la cercanía geográfica del diario y los lectores con el evento ocurrido, su rareza o rasgos particularmente atractivos, su impacto futuro en la sociedad y el compromiso social (Martini y Luchessi, 2004, p. 117).

Esta amplia gama de requisitos para identificar el potencial noticioso de los aconteceres, aunada a las afirmaciones de Berger (1981, p. 18), quien señala que el ser humano debe interiorizar los eventos para transformar la realidad o "factibilidad" objetiva en una estructura subjetiva de sentido por medio del lenguaje, llevan a la conclusión de que la noticia es una especie de discurso que no constituye un retrato exacto de la realidad, sino que es "un marco a través del cual se construye rutinariamente el mundo social" (Van-Dijk, 1996, p. 22).

Hernando (2000, p. 17) distingue tres componentes principales de la noticia. Por un lado, está el titular, dentro del cual se encuentra el título como elemento obligatorio, y de forma optativa pueden incluirse el antetítulo y/o el subtítulo. Posteriormente, aparece el lead o entrada, que es el párrafo inicial y cuya finalidad es responder las preguntas de ¿qué?, ¿quién?, ¿dónde?, ¿cuándo?, ¿por qué? y ¿cómo? en relación con ese acontecimiento que se quiere dar a conocer. 
Por último, el cuerpo de la noticia es donde se desarrolla el resto de detalles sobre lo ocurrido. La información se organiza siguiendo una estructura que se conoce como pirámide invertida (Hernando, 1994, p. 147), en donde hay una disposición decreciente de importancia, de tal manera que si, por razones de falta de espacio, se torna necesario eliminar algún párrafo final del texto, el contenido global no sufre pérdidas significativas de contenido. Esta orientación asigna, entonces, un máximo de relevancia al titular, y sobre todo, al título.

Sánchez (1990, p. 179) reconoce que, al igual que lo hace un nombre propio, la función principal del título es la identificadora: permite distinguir una noticia de las otras que están dentro del periódico. Además, dicho autor concuerda con las afirmaciones de Alarcos-Llorach (1973), quien sostiene que el titular funciona también para seducir al lector. El proceso de seducción involucra la creatividad para destacar aspectos particulares del texto de manera singular e inesperada e incluso podría implicar cierta valoración del contenido. El realce dado a esta información se iconiza con la tipografía seleccionada: letra más grande y en negrita que se destaca en comparación con las otras partes de la noticia.

Secanella (1981, p. 58) identifica como aspecto fundamental del titular su capacidad para condensar, en el menor número de unidades de significación, el contenido de la noticia. Por ende, la autora afirma que "un titular debe ser la síntesis de la noticia; debe recoger el elemento más importante". Este acercamiento hace referencia a su potencial para resumir el contenido del texto, rasgo también destacado por Van-Dijk (1996), para quien el titular condensa la macroestructura semántica del texto. Se presupone que, por medio de macrorreglas como la supresión de lo no relevante, generalizaciones y el reemplazo de detalles de un suceso por una macroproposición que denote el hecho como un todo, se puede reducir la información de un texto a sus temas. De este modo, el titular sería la parte que sintetiza el contenido de manera global. El despliegue paulatino de información íntimamente relacionada con lo expresado en el titular en el resto de la noticia construye la organización temática del texto a partir del principio de coherencia (Van-Dijk, 1996, p. 56).

No obstante, la constitución del titular como resumen no ocurre en todos los casos. Según afirma Zorrilla (1996, p. 59), cuando los títulos periodísticos tienen carácter apelativo o evocador, es necesario recurrir al contexto al que se hace referencia, ya que será este el que permitirá decodificar la intención significativa. María José González (2006) distingue entre titulares verbales, los cuales se componen de un verbo principal y argumentos asociados, y los titulares nominales, que son aquellos compuestos por una frase nominal. González indica que, mientras los primeros tienden a aparecer en diarios de "referencia dominante" e incorporan los principales aconteceres para lograr una representación lingüística del evento, los segundos son característicos de los diarios "de las clases populares" y evidencian el interés por despertar la curiosidad del lector. Los grupos nominales empleados como titulares pueden relacionarse con el contenido de la noticia de una forma muy variada: brindan una interpretación sobre lo ocurrido, enfatizan una determinada perspectiva, etc. Por lo tanto, en ciertas ocasiones, la relación titular-contenido solo podrá deducirse tras leer la noticia.

\section{Marco teórico: las funciones del lenguaje según Jakobson}

Las funciones del lenguaje propuestas por Jakobson permiten aproximarse al estudio del titular desde una perspectiva clásica en lingüística. Se parte, en principio, de un objetivo común independiente del tipo del diario: la construcción lingüística del acontecer social. No obstante, cabe plantearse la interrogante de si, en efecto, en la redacción de un titular, no 
existe ningún compromiso afectivo entre el emisor y el receptor de la información periodística $\mathrm{y}$, por consiguiente, todos los títulos se realizan en el modo declarativo y de manera objetiva -González (2002, p. 139) - o si, por el contrario, el interés por atraer al lector propicia la creatividad lingüística y con ello la elaboración de títulos que enfaticen diferentes funciones del lenguaje, y si este rasgo difiere en La Nación y La Extra.

Roman Jakobson (1984, p. 348), en su empeño por brindar respuesta a la interrogante: ¿qué es lo que hace que un mensaje verbal sea una obra de arte? y por demostrar que la poética debe considerarse parte de la lingüística, proporciona el siguiente esquema en relación con los factores que constituyen el hecho discursivo:

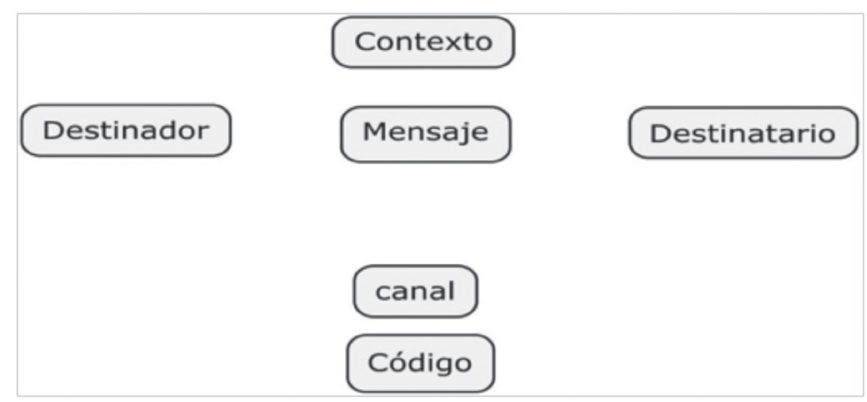

Esquema 1. Factores que constituyen el hecho discursivo según Jakobson

El proceso surge en el destinador (o emisor), quien elabora un mensaje utilizando un código -entendido como el sistema de signos que obedecen reglas organizacionales propias de una lengua y que permiten formular la experiencia- y lo dirige hacia un destinatario (o receptor). Para lograr una interpretación exitosa del mensaje, se requiere de un contexto o punto de referencia compartido entre los participantes en un momento dado y la situación comunicativa determinada, y debe haber entre ellos un contacto o canal físico que haga llegar el mensaje, por ejemplo: un teléfono, un periódico, un televisor.

A partir de este modelo de la comunicación, se derivan las seis funciones del lenguaje, que corresponden a cada uno de los factores tomados en consideración:

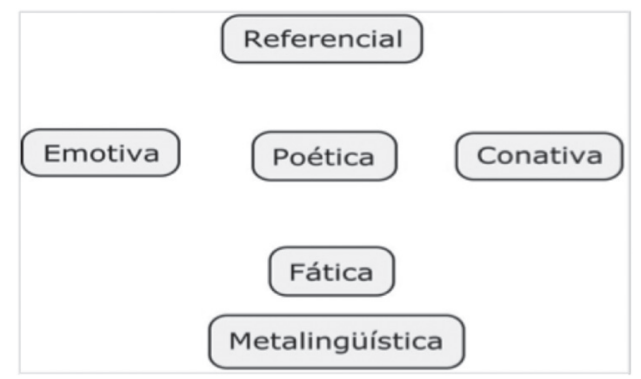

Esquema 2. Las funciones del lenguaje propuestas por Jakobson

La forma que se le asigne a un mensaje -o estructura verbal, en palabras de Jakobson (1984, p. 353) - evidencia el predominio de una o más de estas funciones. La función emotiva (o expresiva) se centra en el destinador y exterioriza la actitud del hablante hacia aquello que transmite. Esta función se puede manifestar con interjecciones, ciertos recursos morfológicos -como diminutivos, aumentativos y despectivos, según el estudio de Valeri (2010) - y también 
por medio de matices fonéticos. Por ejemplo, en inglés, existe la distinción fonológica entre vocales largas (eat /i:t/) y cortas (it/it/). Sin embargo, en palabras donde la extensión vocálica no produce diferencia de significado, dicho recurso puede utilizarse con función potencial emotiva, como ocurre cuando el hablante opta por la forma larga [bi:g] para la palabra big, y con ello proyecta su propia perspectiva y agrega matiz expresivo a lo que se está comunicando.

La función conativa se orienta hacia el destinatario (o receptor), pues se busca influir en su pensamiento o en sus acciones y halla su más pura expresión en el vocativo y el imperativo. El mensaje se emite para provocar una reacción en quien lo recibe, de lo contrario, no se considera efectivo. El imperativo es un modo verbal destinado a emitir órdenes y se considera eficaz en la medida en que esa orden es acatada, y el vocativo es una estructura que permite invocar directamente al interlocutor.

Cuando el mensaje busca establecer un contacto inicial entre las partes (como ocurre con expresiones como oiga, ¿me escucha?, ¡hola!), prolongar la comunicación (sí, ajá, bueno), o bien interrumpirla (¡chao!, ¡adiós!, nos vemos), hay una orientación hacia el contacto o canal y se está recurriendo a la función fática. En ella se busca llamar la atención del interlocutor para atraerlo e involucrarlo, de tal manera que se crea un vínculo destinador-destinatario y un interés en lo que se transmitirá.

La función referencial, conocida también como denotativa o cognoscitiva, se orienta hacia el contexto y surge cuando se transmite información objetiva por medio de oraciones declarativas. Por su parte, la función poética se centra en el mensaje y enfatiza la estética, esto es, se pretende asignar la mejor forma posible a aquello que se desea transmitir, lo cual implica meditar en torno a la selección de las palabras y su combinación. Según Waugh (1980, p. 58), a pesar de ser la función por excelencia de la poesía, no es exclusiva de esta. La creatividad en el lenguaje se ha relacionado con la función poética y se puede presentar en muchos contextos del diario vivir. Maybin y Swann (2007, p. 512) brindan como formas lingüísticas que la caracterizan los juegos de palabras, las figuras literarias y las repeticiones, pues se le asigna una forma más llamativa al mensaje para así dotarlo de atractivo y singularidad.

Por último, para poder alcanzar una decodificación efectiva del mensaje, hay que compartir un mismo código: la misma lengua, dialecto, registro y jerga; de allí proviene la función metalingüística. De acuerdo con Vigara-Tauste (1992, p. 131), esta puede ser explícita cuando "el lenguaje es fuente de conocimiento acerca del propio lenguaje", o bien implícita si es un instrumento que cumple con fines lúdicos como el humor, y en donde se establece un juego "con las posibilidades de relación significante-significado-sentido".

Los indicios lingüísticos descritos en este apartado serán los que se emplearán como guía para identificar el predominio de alguna de las funciones. No obstante, cabe destacar que, en la mayoría de los mensajes, las funciones se integran de un modo jerárquico (Waugh, 1980, p. 58). Lo anterior implica que nunca se llegará a un estado absoluto tal que las diferencias funcionales lleguen a un grado de exclusión, sino que cualquiera de las otras funciones consideradas como no predominantes pueden estar presentes de formas muy variadas y con diferentes grados de importancia.

\section{Metodología}

Para esta investigación de titulares en prensa nacional, se ha seleccionado como representante de diarios de "referencia dominante" La Nación, y La Extra como ejemplar de "las clase populares". Se han recopilado cinco títulos periodísticos por día por diario (excepto 
los domingos, día en el cual no se publica La Extra), durante un mes (del 3 de enero al 3 de febrero del 2014), para un total de 120 títulos por tipo de periódico. Los títulos de La Nación se obtuvieron de la dirección electrónica http://www.nacion.com, y los de La Extra de http:// www.diarioextra.com.

\section{Resultados}

\subsection{El modelo comunicativo de Jakobson aplicado a la noticia en los medios de comunicación escrita}

En los titulares un periodista, en representación del equipo de redacción del diario, puede ser el destinador o emisor primario, lo cual ocurre cuando se reconstruye con el lenguaje esos aconteceres que se consideran importantes dentro de una comunidad:

(1) Cristiano Ronaldo ganó el Balón de Oro con una ventaja mayor al 3\% de los votos sobre Lionel Messi (LN, 13.01.2014).

Otra posibilidad es reproducir las palabras de alguna fuente primaria, cuya participación, ya sea por su relevancia a nivel social o por ser testigo o protagonista de acontecimientos, resulta ser más llamativa que la del periodista. En ese caso el periodista pasa a ser un emisor secundario:

(2) Jorge Luis Pinto asegura que la Selección Nacional exigirá a Chile en juego amistoso (LN, 07.01.2014)

El segundo elemento constitutivo del esquema de comunicación es el destinatario, el cual, en el discurso en prensa escrita, está conformado por una multitud que asume el papel colectivo denominado lector. Debido a que la cercanía geográfica destaca dentro de los principios de noticiablidad, se presupone que la figura del lector estará compuesta por ciudadanos que comparten el mismo territorio del lugar de producción e impresión del periódico. No obstante, cada diario se especializa en un público meta diferente pues, mientras que La Nación se autodefine para los costarricenses de niveles educativos alto y medio (Grupo Nación, 2014), La Extra se proyecta a la comunidad sin hacer distinciones de nivel educativo, por cuanto busca ser el medio de comunicación del pueblo.

En consecuencia, la forma que se le asigne al mensaje puede variar según la definición del tipo de lector y los objetivos del periódico (ya sea informar de forma seria y objetiva, en el caso de La Nación, o informar y entretener, para La Extra). Por lo tanto, en ambos diarios el mensaje hará alusión al referente por medio de la lengua española, que funciona como código, pero puede haber variaciones intencionadas en relación con el tipo de registro. De hecho, Hernando (2002, p. 265) menciona que el usuario de la lengua puede elegir entre una estructura objetiva y neutral o una subjetiva en donde lo imaginativo y lo afectivo se superpone a lo puramente conceptual. Para ejemplificar este punto, se pueden citar los siguientes títulos:

(3) Tata Martino dice que Messi ha regresado "con mirada asesina" (LN, 04.01.2014)

(4) Como locos con Messi (LE, 04.01.2014) 
Los casos anteriores muestran que, a partir de un mismo acontecer referencial, se estructuran enunciados muy diversos, cada uno de los cuales conlleva sus propias interpretaciones. Aquí, lo sucedido fue que Lionel Messi regresó a los entrenamientos después de 54 días de estar lesionado. En La Nación se ha decidido presentar lo ocurrido a partir de la impresión que el hecho suscitó en el director técnico del Barcelona, Gerardo Martino. Por su parte, en el diario La Extra, se da a conocer el mismo evento, pero interesa captar el entusiasmo que generó entre los aficionados presentes durante la práctica. Además, cabe destacar que el registro en la sección deportes es más informal que en otras secciones, incluso en La Nación, en donde se ha empleado el apodo Tata en lugar del nombre propio del entrenador. El título de La Extra también muestra la tendencia a estructurar el mensaje elidiendo verbos estativos (como ser o estar) y se emplea la expresión popular como locos, para transmitir la euforia de la afición.

La selección de registro informal y de léxico propio del sociolecto costarricense es efectiva en La Extra porque tiene el potencial de provocar simpatía en el lector, por cuanto muestra la existencia de códigos lingüísticos y culturales compartidos. Al respecto, afirma Bermúdez (1990, p. 59) que los sectores populares se identifican con el discurso del diario porque creen reconocerse en él. El mismo contenido podría encontrarse en otros diarios; por eso, la manera más efectiva de atraer al lector es empleando el código que le resulte más familiar y que le genere confianza.

Por último, el canal empleado por los periódicos para establecer la comunicación es el papel. Al respecto, afirma Tusón-Valls (2003, p. 43) que este material es el soporte más frecuente y demanda una disposición particular de los elementos, para que el régimen visual entre en acción y logre atraer al destinatario.

\subsection{Las funciones del lenguaje de Jakobson aplicadas a los títulos periodísticos}

Los títulos periodísticos comparten, independientemente del tipo de diario, el objetivo primordial de llamar la atención del lector, atraerlo y motivarlo a adquirir el diario. Para ello, se codifica en el título la información que tiene la capacidad de cumplir con este objetivo y, además, se utilizan estrategias tipográficas (como el tamaño mayor de la letra y el uso de formato en negrita) que permiten destacar este enunciado del resto del texto. Cumplen, por ende, con la función fática: establecer el contacto inicial con el lector. Cuvardic y Vargas (2010, p. 208) concuerdan en este punto y reconocen que los titulares no solo establecen la comunicación entre el lector y el diario, sino que muchas veces se convierten en la única información que al lector le interesa obtener del diario, debido a que podrían darse por satisfechos con su simple lectura. Dentro del contexto periodístico, los titulares están diseñados para establecer ese primer contacto con el lector, y así señalarle que se está dispuesto a iniciar la comunicación: depende del lector si quiere responder a este llamado al adquirir el diario.

Ahora bien, Jakobson (1984, p. 66) reconoce que "we could hardly find verbal messages that would fulfill only one function". Es decir, un título podría enfatizar una o más funciones del lenguaje, las cuales se pueden identificar según la forma que se asigna al mensaje y los significados que se desprendan a partir del enunciado.

En muchos títulos se selecciona el modo declarativo para dar a conocer, de manera objetiva, un acontecimiento novedoso que ha ocurrido en el contexto social. Se privilegia, entonces, la función referencial. Ahora bien, en vista de que la realidad es un continuum 
mientras que el lenguaje es lineal, se necesita adoptar un orden sintáctico específico en el cual se codificará el enunciado. Esto conduce a que, aun si se seleccionan las oraciones declarativas como mecanismo óptimo para transmitir información, existen opciones para presentar el acontecimiento:

(5) Futbolistas buscarán becas en universidades de EE.UU. (LE, 23.01.2014)

(6) En Liberia nace una joya de estadio (LE, 09.01.2014)

(7) Con Keylor Navas en el arco, Levante cayó 2-0 en visita a Valencia (LN, 04.01.2014)

Los ejemplos (5), (6) y (7) muestran que, a nivel sintáctico, existe la posibilidad de colocar como punto de partida el elemento que se considere más pertinente, llamativo, o que pueda captar mejor la atención del lector. Así, mientras que en el ejemplo (5) se inicia la oración a partir del sujeto, selección más numerosa en la titulación nacional de acuerdo con los resultados en la investigación de Vargas (2012, p. 208), en el (6) se prefiere estructurar el enunciado a partir de un adjunto que indica el lugar en donde están ocurriendo las acciones y en el (7) se construye el mensaje a partir de un elemento codificado como adjunto de compañía y se brinda, de esa manera, una perspectiva específica a partir de la cual se debe interpretar el triunfo del equipo.

Algunos títulos de la sección deportiva de ambos periódicos emplean diversos recursos lingüísticos para atraer la atención del interlocutor. Afirman Calsamiglia y Tusón (2008) que la creatividad en el lenguaje, ya sea producto de la vida cotidiana o por elaboración de escritores u oradores, ocupa un espacio estético por vincular la imaginación con el uso del lenguaje. En estos casos, el éxito se alcanza gracias a la combinación de la función referencial con la estética (Waugh, 1980, p. 59), ya que la variación en la forma del mensaje intensifica el interés por parte del lector:

(8) Real Madrid tras la caza del Barcelona y Atlético de Madrid en el fútbol español (LN, 24.01.2014)

(9) En Liberia nace una joya de estadio (LE, 09.01.2014)

(10) Nueva York vibra con la fiesta del Super Bowl (LE, 1.02.2014)

La forma asignada a estos enunciados desautomatiza la percepción, lo cual incrementa el atractivo del titular (Cuvardic y Vargas, 2010, p. 218). El uso de tropos implica el traslado semántico producido por las nuevas relaciones que emergen entre los significados lingüísticos y los referentes, por cuanto permiten interpretar la realidad al propiciarse el empleo de un término con mayor valor expresivo (García-Barrientos, 2000, p. 52). Por ejemplo, en el título (8) de La Nación, se compara la disputa del primer lugar en el fútbol español con la lucha por la sobrevivencia propia de la selva, ya que se equipara al Real Madrid con un depredador, imagen lograda por medio del término caza, y al Barcelona y Atlético de Madrid se les asigna el papel de presas.

En La Extra también se registraron títulos de este corte, como se muestra en los ejemplos (9) y (10). En el primero se emplea una metáfora para describir el aspecto y la calidad del estadio construido en Liberia. Esta se ha elaborado utilizando un antiguo atributo (el 
estadio es una joya) y convirtiéndolo en el núcleo del sintagma nominal complementado por el antiguo sujeto (joya de estadio), estructura que Gutiérrez-Ordoñez (2000, p. 39) denomina adyacente nominal atributivo. En el segundo, Nueva York vibra con la fiesta del Super Bowl, se hace uso de una metonimia, en donde el nombre de la ciudad (Nueva York) se usa para designar a sus habitantes (los neoyorkinos).

Como se mencionó anteriormente, se presupone que en la forma asignada al título periodístico debe distanciarse de compromisos afectivos (González, 2002), lo cual implicaría la selección de formas impersonales que se dediquen a transmitir la información, sin valorarla. En efecto, así sucede en la mayoría de los títulos de La Nación. No obstante, en La Extra existe mayor libertad para interactuar con el contenido del mensaje, de tal manera que el emisor puede manifestar, de algún modo, la propia percepción sobre el acontecimiento y, por lo tanto, se privilegia la función emotiva:

(11) Ayudita al Monstruo y zancadilla a Cartaguito (LE, 17.01.2014)

(12) Kenianos resultaron unos paquetazos (LE, 03.01.2014)

(13) ;Maratón de fútbol fue un exitazo! (LE, 08.01.2014)

De acuerdo con la Real Academia Española -RAE- (2010, p. 163), los sufijos apreciativos "se añaden para expresar la valoración afectiva que se hace de las personas o las cosas". En el ejemplo (11) se emplea el diminutivo -ito/a en el sustantivo ayudita (cuyo significado corresponde al de tamaño reducido: una pequeña ayuda) y Cartaguito (uso que puede transmitir un matiz afectivo). Su alta expresividad lleva a excluirlos de los textos cuyo contenido busque la objetividad. En La Extra, también se utiliza la sufijación aumentativa (-azo/a), ya sea con un efecto de significado que intensifica en términos positivos, como en el ejemplo (12), o en negativos, como en (13).

Otra forma de identificar la inclinación hacia en la función emotiva es por medio de interjecciones, uso que se registró en el siguiente caso:

(14) ¡Ay Uruguay! te paseaste en la pulseada santista (LE, 17.01.2014)

Las interjecciones son una clase de palabras que forma enunciados exclamativos, dentro de los cuales se ponen de manifiesto diferentes reacciones afectivas. La palabra no describe la sensación, sino que la manifiesta en sí misma (RAE, 2010, p. 623). En el ejemplo (14) la interjección ay manifiesta tristeza o desasosiego por parte del emisor, en relación con el actuar del equipo uruguayo.

Otros títulos de La Extra se centran en la función conativa; es decir, el énfasis está en el destinatario. Jakobson (1984, p. 68) sostiene que "orientation toward the addressee, the CONATIVE function, finds its purest grammatical expression in the vocative and imperative". Así, algunos ejemplos en donde se emplea el vocativo son:

(15) “Schumi”, feliz cumple y que te recuperes (LE, 03.01.2014)

(16) Vamos muchachas, sí se puede (LE, 17.01.2014)

(17) ;Bienvenidas, mundialistas! (LE, 22.01.2014)

(18) ¡Che, qué bien los ticos! (LE, 21.01.2014) 
Los ejemplos (15), (16) y (17) se estructuran apelando a quien protagonizó la noticia. En La Extra se tiende a asignar dicha forma al título cuando el diario asume la voz del pueblo. Por lo tanto, si se considera que existe un sentimiento de solidaridad del costarricense hacia alguien en particular, el título le comunica a esa persona las emociones de la población. Así, el ejemplo (15) se dirige a Michael Schumacher, campeón de Fórmula 1, quien tiempo atrás se había caracterizado por su humildad y había brindado su apoyo durante el terremoto de Cinchona, pero que ese día, el de su cumpleaños, se encontraba internado tras sufrir un grave accidente. La emotividad que busca crear el título se refuerza con el subtítulo: Nunca olvidaremos su paso por Tiquicia.

Por su parte, los títulos (16) y (17) apelan a la selección sub-20 femenina. Primero, en (16) se emplea una interjección apelativa no formularia que transmite ánimo, y junto a esta palabra aparece el vocativo para especificar a quién se dirige ese estímulo positivo. Días después, aparece de nuevo un título -el (17) - que apela a ellas, para darles la bienvenida, ya que habían logrado la clasificación al mundial de Canadá, por cuando se considera que su regreso al país es motivo de orgullo y alegría a nivel nacional.

Asimismo, en el ejemplo (18) se emplea el vocativo por excelencia del sociolecto argentino con el fin de apelar al lector y hacerle saber el buen desempeño de sus compatriotas. Para esto, se imita la forma de hablar del lugar en donde se encontraban Gregory Brenes y Andrey Amador, participando del Tour de San Luis. de plural:

En algunos títulos se empleó el imperativo en segunda persona tanto de singular como

(19) ¡Lávese la cara! (LE, 25.01.2014)

(20) ;Denle las gracias a Pemberton! (LE, 30.01.2014)

En el ejemplo (19) se ha escogido un título que da una orden y el subtítulo ayuda a identificar la identidad de ese individuo a quien va dirigido el mandato: "Sele" salta de nuevo a la cancha esta noche. En efecto, quienes han de lavarse la cara (enunciado usado con significado figurativo pues lo que implica es que se debe dar una mejor imagen de sí mismo) son los jugadores de la Selección Nacional de Fútbol. Por su parte, el título (20) se dirige a los lectores que apoyan al Club Sport Herediano, y se les indica que el triunfo del partido frente a la Liga Deportiva Alajuelense se logró con el apoyo sobresaliente de Patrick Pemberton, por cuanto se les insta a agradecerle.

Por último, en cuanto a la función metalingüística, es importante resaltar las palabras de Vigara-Tauste (1992), quien distingue entre la metafunción lingüística explícita e implícita. La primera es cuando el lenguaje reflexiona sobre sí mismo, es decir, el referente es el propio lenguaje, como ocurriría en la oración ecuativa: un actor es un hombre que interpreta un papel en el teatro, el cine, la radio o la televisión. La segunda surge cuando se desautomatiza la decodificación al romperse el esquema convencional significante/significado, procedimiento que sirve para finalidades lúdicas o de humor, entre otras. Aparece, entonces, una reflexión sobre el código y su funcionamiento para emprender un juego de posibilidades de relación significado-significante-sentido (Vigara-Tauste, 1992, p. 131). Esta reflexión implícita sobre el código se emplea en el siguiente título de La Extra:

(21) Barça con toda la “Elche” (LE, 06.01.2014) 
En el ejemplo (21) la reflexión sobre el código se hace evidente cuando se emplea el nombre del equipo de fútbol Elche, de la provincia de Alicante, para establecer un juego de significante/significado. El título toma como punto de partida la similitud fonética y ortográfica entre los términos Elche y leche para hacer mención al gane del equipo de Barcelona frente al Elche a través de la expresión popular con toda la leche, que significa estar lleno de energía.

Los apellidos y los apodos de los deportistas también sirven como herramienta para el juego significante/significado:

(22) ;Messi-ento como nuevo! (LE, 17.01.2014)

(23) Tello dije que se vengaba (LE, 23.01.2014)

(24) “Carmencita” sacó la faja y la Liga la dejó “caya”-dita (LE, 13.01.2014)

En estos casos el significante alcanza un doble significado. El referente siempre será importante para decodificar el contenido de la noticia, pero el significado agregado es relevante para provocar el giro humorístico o inesperado. En el ejemplo (22) se emplea como base el apellido del jugador Lionel Messi para conformar el predicado me siento, con lo cual se estaría dando a conocer el grado de satisfacción que dicho jugador tendría sobre sí mismo al haber mostrado un buen desempeño en un partido, luego de haber sobrellevado una lesión. En el título (23) se establece un juego semántico bastante similar al del (22), pues se utiliza el apellido del jugador del Barcelona, Cristian Tello, para crear el enunciado: te lo dije que se vengaba. El juego deviene, entonces, de las similitudes fonéticas entre Tello y los pronombres átonos te lo, pero se respeta la grafía del apellido precisamente para resaltar la doble significación.

En el ejemplo (24) la función metatextual implícita surge a partir de un sobrenombre. En él se remite al hecho de que la intervención del jugador de la liga, Armando Alonso (El Caya) condujo al triunfo de su equipo, por cuanto el equipo contrario se quedó calladito, sin comentarios ante la derrota. Una vez más, se emplea como punto de partida para establecer la reflexión intencionada en torno al código la fonética (Caya/ caya-dita) y la escritura remite al referente (el jugador), aspecto que se enfatiza por medio del guión.

Otros ejemplos que podrían vincularse con la función metalingüística indirecta son los que se construyen utilizando frases célebres. Pano (2012) afirma que esta función se apoya en el conocimiento del receptor sobre código y la cultura lingüística que comparten. Por eso, menciona la intertextualidad como un mecanismo que "conduce a información lingüística asociada a otro contexto y que es posible recontextualizar por medio de la conducta metalingüística" (Pano, 2012, p. 614). En este sentido, pueden citarse los siguientes títulos:

(25) En Limón no cunde el pánico (LE, 22.01.2014)

(26) Goleando bajo la lluvia (LE, 30.01.2014)

En los ejemplos (25) y (26), también de La Extra, se establecen intertextos, o más específicamente, procedimientos interdiscursivos (entendidos por Plett (1991) como polifonía textual dialógica con ideas ajenas tomadas de arte como pintura, música, cine, canción, entre otros) que remiten a producciones altamente conocidas por los lectores. La expresión en (25) -no cunde el pánico- es una famosa frase del Chapulín Colorado, y el enunciado en el título 
(26) -Goleando bajo la lluvia- establece un paralelismo con el título de la película Cantando bajo la lluvia; incluso se emplea el gerundio del verbo golear para intensificar la similitud con dicha producción cinematográfica. Entonces, estos titulares asumen la existencia de conocimientos compartidos con el lector, ya que se necesita cierto bagaje contextual y cultural para que su decodificación sea efectiva.

\section{Conclusiones}

Los títulos periodísticos codifican un mensaje dirigido hacia el lector $\mathrm{y}$, en este proceso comunicativo, intervienen los seis elementos esquematizados por Jakobson, aunque cada uno adquiere características propias. El emisor, sea primario o secundario, transmite información relacionada con un referente, una realidad externa. No obstante, no todos los acontecimientos ocurridos alcanzan el estatus de noticia; solo unos cuantos serán seleccionados, según los criterios de noticiabilidad. Por su parte, el receptor propicia la selección de un código, sea formal o informal, estándar o dialectal, lo cual posibilita distinguir entre titulares impersonales y aquellos que buscan establecer algún grado de cercanía con el lector.

Las funciones del lenguaje de Jakobson ayudan a comprender mejor el papel que tiene cada factor del hecho discursivo y, por ende, a identificar el énfasis de cada enunciado. En la mayoría de los titulares, se acentúan las funciones referencial y fática: interesa establecer la comunicación con el lector e informarlo sobre cierto acontecer relevante ocurrido en la realidad extralingüística. Esto es así tanto en los títulos de los periódicos de referencia como en los de "las clases populares".

No obstante, los resultados del presente estudio permitieron concluir que, en la sección deportiva, tanto en el periódico La Nación como en La Extra, es factible que los titulares se inclinen hacia la función poética, es decir, se explota la creatividad lingüística para favorecer la estética del mensaje. Además, en este último diario se amplía la gama de posibilidades, pues también se registraron títulos que privilegiaban otras funciones, ya sea la emotiva, la conativa o la metalingüística implícita, lo cual demuestra la existencia de un interés mucho mayor, no solo de informar, sino de atraer al lector al apelar a interlocutores específicos, al estructurar el título como mandato, al interactuar con el contenido del mensaje o bien al transgredir el vínculo convencional significante-significado para confeccionar el título. Con todo lo anterior, se busca satisfacer el objetivo de producción de este tipo de diario: informar y entretener.

\section{Notas}

1. En prensa escrita autores como Sunkel (2002) y Samiolo (2008, pp. 43-50) distinguen dos claras tendencias: periódicos de "referencia dominante" frente a diarios de "las clases populares". Los primeros se caracterizan por transmitir noticias serias, utilizar vocabulario estándar y emplear oraciones extensas, por medio de recursos sintácticos como la coordinación y subordinación. Este tipo de prensa goza de alta credibilidad por parte de la población. Los diarios de "las clases populares", buscan informar y, al mismo tiempo, entretener al lector; por lo tanto, transmiten noticias serias, pero también triviales. En ellos se hace uso de un tipo de vocabulario informal, al cual Sunkel (2002, p. 109) denomina lenguaje popular, y une tanto rasgos propios del sociolecto al cual se dirige la publicación como expresiones populares del español en general. A nivel sintáctico, hay una tendencia hacia la oración simple, rasgo que facilita la lectura. Para los diarios en Costa Rica, autores como Cuvardic y Vargas (2010), Bustos (2004-2005) y Fonseca (2005) han encontrado consonancia entre las características de los periódicos de "referencia dominante" con La Nación, mientras que el uso del lenguaje popular acerca a La Extra con los de "las clases populares". 


\section{Bibliografía}

Alarcos-Llorach, E. (1973). "El lenguaje de los titulares". Por F. Lázaro-Carreter (Comp.). Lenguaje en periodismo escrito. (125-147). Madrid: Fundación Juan March.

Berger, P.L. (1981). Para una teoría sociológica de la religión. Barcelona: Kairós.

Bermúdez, M. (1990). La Extra: ¿Representación de las clases populares? Revista de Ciencias Sociales. 47, 55-65.

Bustos, G. (2004-2005). Ciencia y tecnología en la prensa escrita costarricense: análisis de casos. Revista de Ciencias Sociales. 106 (4) - 107 (1), 215-229.

Calsamiglia, H. y Tusón, A. (2008). Las cosas del decir. Manual de análisis del discurso. Barcelona: Ariel.

Colombo, F. (1997). Últimas noticias sobre el periodismo. Barcelona: Anagrama.

Cuvardic, D. y Vargas, E. (2010). Recursos lingüísticos en la titulación periodística costarricense: el caso de La Nación y el diario La Extra. Revista de Filología y Lingüística de la Universidad de Costa Rica. 36 (1), 207-232.

Fonseca, K. (2005). Noticias de sucesos y criminalidad: de los textos periodísticos a la recepción empírica. (Tesis de Licenciatura en Ciencias de la Comunicación). Universidad de Costa Rica.

García-Barrientos, J.L. (2000). Las figuras retóricas. El lenguaje literario 2. Madrid: Alarcos.

González, M.J. (2002). La incidencia de la dimensión contextual en la producción del título periodístico. Atlantis, Revista de la Asociación Española de estudios AngloNorteamericanos. 24 (2), 329-48.

González, M. J. (2006). Complejidad del grupo nominal en la descripción y diferenciación de variedades del lenguaje: un estudio de estilística. Revista de Lingüística Teórica y Aplicada. 44 (2), 29-46.

Grupo Nación. (2014). Estudio de medios. http://www.nacionmediakit.com/contenido/. [Consulta 15 de abril de 2014].

Gutiérrez-Ordóñez, S. (2000). Temas, remas, focos, tópicos y comentarios. Madrid: Arco.

Hernando, L.A. (1994). Comunicación y lenguaje en el periodismo escrito. Didáctica, Revista de la Universidad Complutense de Madrid. 6, 145-159.

Hernando, L.A. (2000). Discurso periodístico. Madrid: Editorial Verbum.

Hernando, L.A. (2002). Sobre la configuración lingüística del mensaje periodístico. Estudios sobre el mensaje periodístico. 8, 261-274.

Jakobson, R. (1984). Lingüística y poética. Ensayos de lingüística general. (347-395). Barcelona: Ariel.

Lázaro-Carreter, F. (Comp.). (1973). Lenguaje en periodismo escrito. Madrid: Fundación Juan March.

Martini, S. (2000). Periodismo, noticia y noticiabilidad. Barcelona: Norma.

Martini, S. y Luchessi, L. (2004). Los que hacen la noticia. Periodismo, información y poder. Buenos Aires: Biblos. 
Maybin, J. y Swann, J. (2007). Everyday Creativity in Language: Textuality, Contextuality, and Critique. Applied Linguistics. 28 (4), 497-517.

Pano, A. (2012). Funciones metalingüísticas y dobles lecturas del código: estudio introductorio de F. Lázaro-Carreter. Por A. Cassol et ál. (Eds.). Metalinguaggi e metatesti. Lingua, letteratura e traduzione, XXIV Congresso AISPI (23-26 maggio 2007). Padova. (607616).

Plett, H. (Ed.) (1991). Intertextuality. Berlín-Nueva York: Walter de Gruyter.

Real Academia Española. (2010). Manual de la nueva gramática de la lengua española. México: Espasa.

Samiolo, S. (2008). Semantic Styles in the British Daily Press: A Corpus Study. (Tesi di dottoratoin Scienze Linguistiche, Filologiche e Letterarie). Università degli Studi di Pavoda.

Sánchez, J.F. (1990). Títulos y titulares. Sobre las funciones de la titulación periodística. Comunicación y Sociedad. 3 (1 y 2), 173-183.

Secanella, P. (1981). El lid, fórmula inicial de la noticia. Barcelona: Editorial ATE.

Sunkel, G. (2002). La prensa sensacionalista y los sectores populares. Bogotá: Editorial Norma.

Tusón-Valls, J. (2003). Introducción al lenguaje. Barcelona: Ariel.

Valeri, M.J. (2010). Los sufijos apreciativos -ito, -ico y -ón en cartas escritas en Mérida colonial. Lingua Americana. 14 (26), 15-33.

Van-Dijk, T. (1996). La noticia como discurso. Barcelona: Paidós.

Vargas, E. (2012). La metafunción textual en los titulares periodísticos costarricenses. (Tesis de Maestría Académica en Lingüística). Universidad de Costa Rica.

Vigara-Tauste, A.M. (1992). Función metalingüística y uso del lenguaje. Epos, Revista de Filología de Madrid. 8, 123-141.

Zorrilla-Barroso, J. M. (1996). El titular de la noticia. (Tesis doctoral). Universidad Complutense de Madrid.

Waugh, L. (1980). The Poetic Function in the Theory of Roman Jakobson. Poetics Today. 2(la), 57-82. 